\title{
Differential Responses to Systemic and Local Angiotensin II Infusions in Conscious Postnatal Sheep
}

\author{
SITHEMBISO C. VELAPHI, TIMOTHY ROY, KEVIN DESPAIN, AND CHARLES R. ROSENFELD \\ Division of Neonatal-Perinatal Medicine, Department of Pediatrics, University of Texas Southwestern \\ Medical Center at Dallas, Dallas, Texas 75390-9063, U.S.A.
}

\begin{abstract}
Angiotensin II (ANG II) increases blood pressure (MAP) via specific ANG II receptors (AT) and is considered important in regulating MAP after birth. In adult animals, $\mathrm{AT}_{1}$ receptors predominate in vascular smooth muscle (VSM) and mediate vasoconstriction. In newborn sheep, $\mathrm{AT}_{2}$ receptors, which do not mediate vasoconstriction, predominate in vascular smooth muscle until $2 \mathrm{wk}$ postnatal when they are replaced by $\mathrm{AT}_{1}$. Thus, the mechanisms whereby ANG II increases MAP after birth are unclear. We examined the effects of ANG II on femoral vascular resistance (FmVR) and blood flow $(\mathrm{FmBF})$ in serial studies of newborn sheep $(n=7)$ at 7-14 d, 15-21 d, and 22-35 d. Animals had femoral catheters implanted for systemic ANG II infusions and cardiovascular monitoring, and a flow probe was implanted on the contralateral artery proximal to the superficial saphenous artery, which contained a catheter for intra-arterial ANG II infusions. Studies were performed using a range of systemic and intra-arterial ANG II doses. Systemic ANG II increased MAP dose-dependently at all ages $(p<0.001)$; however, responses were not age dependent. FmBF rose dose dependently at 7-14 d $(p<0.001)$ and was unchanged at older ages. FmVR was unaffected at 7-14 d, but values increased dose dependently at 15-21 d and 22-3 5d $(p<0.001)$, although never exceeded
\end{abstract}

\section{ABSTRACT}

relative increases in MAP. Local ANG II did not alter MAP, FmBF, or FmVR at any age. Although systemic ANG II increases MAP and FmVR dose dependently after birth, ANG II-induced vasoconstriction is attenuated. Furthermore, intraarterial ANG II does not alter FmVR in the absence of systemic responses, suggesting incomplete vascular smooth muscle $\mathrm{AT}_{1}$ expression, stimulation of local ANG II antagonists, or ANG II-mediated release of another vasoconstrictor. (Pediatr Res 52: 333-341, 2002)
ANG II, angiotensin II
Abbreviations
AT, angiotensin II receptor
$\mathbf{A T}_{1}$, angiotensin II receptor subtype 1
$\mathbf{A T}_{\mathbf{2}}$, angiotensin II receptor subtype 2
FmBF, femoral blood flow
FmVR, femoral vascular resistance
HR, heart rate
PVR, peripheral vascular resistance
VSM, vascular smooth muscle
$\% \Delta$, percent change

The transition from fetal to newborn life is associated with numerous hemodynamic changes, including alterations in HR, blood pressure, PVR, and the distribution of cardiac output $(1-4)$. The autonomic nervous system and the reninangiotensin system (RAS) are considered important modulators of the cardiovascular changes in the perinatal period. This is supported by evidence of increased circulating levels of catecholamines and ANG II during and after parturition (1, 4-6). ANG II is the predominant vasoactive agent associated

Received June 7, 2001; accepted March 22, 2002.

Correspondence: Charles R. Rosenfeld, M.D., Department of Pediatrics, University of Texas Southwestern Medical Center at Dallas, 5323 Harry Hines Blvd., Dallas, TX 75390-9063, U.S.A.; e-mail: charles.rosenfeld@utsouthwestern.edu

Supported in part by the George L. MacGregor Professorship in Pediatrics and National Institutes of Health Grant HD-08783.

DOI: 10.1203/01.PDR.0000030714.99576.AE with the RAS and is believed to be an important regulator of blood pressure in fetal, neonatal, and adult sheep (7-9). The effects of ANG II on blood pressure may reflect its direct action on VSM through increases in PVR or on cardiac output by increasing venous return or HR $(4,10-13)$. Indirect effects on VSM also may occur through activation of central autonomic nervous system activity or the release of other vasoactive mediators $(11,14-16)$.

ANG II mediates its actions by binding to specific AT. At least two $\mathrm{AT}$ subtypes have been identified, $\mathrm{AT}_{1}$ and $\mathrm{AT}_{2}$, and their expression is developmentally regulated (17-19). In the adult, the $\mathrm{AT}_{1}$ is the primary subtype expressed in most tissues, including VSM, and accounts for most biologic actions of ANG II $(20,21)$. However, $\mathrm{AT}_{2}$ are found in selective adult tissues, e.g. adrenal, myometrium, and uterine arteries from pregnant and nonpregnant women and sheep (9, 21-23). Ex- 
cept for umbilical VSM, it is the primary subtype expressed in systemic artery VSM of near-term fetal sheep and up to $2 \mathrm{wk}$ postnatal, after which there is a transition from $\mathrm{AT}_{2}$ to $\mathrm{AT}_{1}$ predominance that is complete by 3 mo postnatal (18). Activation of $\mathrm{AT}_{1}$ occurs via $\mathrm{G}$-protein coupling, which results in phosphoinositol-phospholipase $\mathrm{C}$ activation, calcium mobilization, and VSM contraction. $\mathrm{AT}_{2}$ activation does not result in any of the above, including VSM contraction (20). Although $\mathrm{AT}_{2}$ may oppose $\mathrm{AT}_{1}$ mediated responses, the function of $\mathrm{AT}_{2}$ is incompletely understood $(19,24,25)$.

Because $\mathrm{AT}_{2}$ appear to predominate in fetal and early postnatal ovine VSM, it is unclear how ANG II modulates blood pressure. Kaiser et al. (26) reported that although $\mathrm{AT}_{2}$ appear to predominate in femoral VSM in term fetal sheep systemic ANG II infusions increased FmVR. However, these responses were proportionate to and parallel with the rise in mean arterial pressure (MAP), suggesting peripheral autoregulation and/or local myogenic responses (27). In contrast, increases in umbilical vascular resistance exceeded increases in MAP, demonstrating a direct vasoconstrictor effect consistent with predominate $\mathrm{AT}_{1}$ expression $(18,19)$ that was inhibited by local infusion of losartan, an $\mathrm{AT}_{1}$-specific antagonist. Thus, responses in these two vascular beds to i.v. ANG II were believed to reflect the differences in AT subtype expression. In adult sheep, which express $\mathrm{AT}_{1}$ in nearly all VSM (21), systemic ANG II increases MAP (13), and local intra-arterial ANG II infusions increase hindlimb vascular resistance (10), suggesting that the rise in MAP results from a direct peripheral vasoconstrictor effect and responses in the hindlimb might mirror responses in other vascular beds. In newborn sheep, systemic ANG II infusions also increase systemic vascular resistance and MAP (28-30). However, because $\mathrm{AT}_{2}$ receptors appear to predominate in VSM after birth and do not mediate VSM contraction $(18,20)$, the mechanisms whereby ANG II modulates neonatal MAP and PVR in the first month postnatal are unclear.

In view of the discrepancy between AT subtype expression in neonatal VSM and the pressor responses to i.v. or systemic ANG II infusions, we examined the mechanisms of ANG II-mediated vasoconstriction and increases in MAP by comparing the effects of local intra-arterial and i.v. ANG II infusions on PVR in conscious neonatal sheep, represented by the hindlimb vascular bed. This approach would potentially separate direct and indirect ANG II-mediated responses in the hindlimb of newborn sheep.

\section{METHODS}

Animal preparation. Seven newborn sheep were studied between 7 and $35 \mathrm{~d}$ postnatal. Surgery was performed at 3-5 d of life. Preoperatively, each animal received s.c. atropine $(0.088 \mathrm{mg} / \mathrm{kg})$ followed by i.v. sodium pentobarbital (7.5-10 $\mathrm{mg} / \mathrm{kg}$ ) and $1 \%$ ketamine hydrochloride $(1-2 \mathrm{mg} / \mathrm{kg}$ ) via a percutaneous jugular catheter. During surgery, $1 \%$ ketamine hydrochloride $(1 \mathrm{mg} / \mathrm{kg})$ was given i.v. to maintain deep anesthesia. Through an inguinal incision in one hindlimb, the femoral artery and vein were identified and dissected. Two polyvinyl catheters containing heparinized saline (250 units/
$\mathrm{mL}$ ) were implanted $12.5 \mathrm{~cm}$ and $7.5 \mathrm{~cm}$ in the femoral artery for cardiovascular monitoring and blood sampling, respectively. A femoral venous catheter was placed $15 \mathrm{~cm}$ so that the tip was above the bifurcation of the inferior vena cava and was used for administration of systemic infusions of ANG II. An inguinal incision was made in the contralateral hindlimb, and the femoral artery was dissected; a $3.0-4.0 \mathrm{~mm}$ electromagnetic flow probe (Carolina Medical, King, NC, U.S.A.) was implanted proximal to the branching of the superficial saphenous artery to continuously measure FmBF. A polyethylene catheter (PE 50) filled with heparinized saline (250 units $/ \mathrm{mL}$ ) was then inserted into the superficial saphenous artery with the tip lying at the junction with the femoral artery for intra-arterial ANG II infusions. The catheters were flushed with heparinized saline $(250$ units $/ \mathrm{mL})$ and closed with metal pins. The flow probe leads and catheters were brought out to the flank through a s.c. tunnel and placed in a canvas pouch attached to the skin with sterile steel pins. The skin incisions were closed in one layer with surgical staples. During surgery, the animals were infused with $10 \%$ dextrose and isotonic saline at $20 \mathrm{~mL} / \mathrm{kg} \cdot \mathrm{hr}$ to prevent hypoglycemia and hypovolemia. All animals received i.v. banamine $(0.1 \mathrm{~mL}$; Schering-Plough Animal Health, Union, NJ, U.S.A.) for pain and intramuscular penicillin $(60,000$ units) and gentamicin $(7.5 \mathrm{mg})$ for prophylaxis after surgery and on the first two postoperative days. Immediately after surgery, animals were infused with $70 \mathrm{~mL} / \mathrm{kg}$ of $5 \%$ dextrose and isotonic saline over $4 \mathrm{~h}$ and were maintained under a heated warmer until they had fully recovered from the anesthesia. After recovery, animals were returned to their mothers for feeding, but were removed the first night and kept in a postoperative recovery facility within the Animal Resources Center for close monitoring and bottle feeding. Subsequently, each animal was kept with its mother except during the time of an experiment. Catheters were flushed daily with sterile heparinized saline ( 250 units $/ \mathrm{mL}$ ) to maintain patency. All animals received intramuscular penicillin (60,000 units) and gentamicin $(7.5 \mathrm{mg})$ at the completion of each study for prophylaxis.

Experimental protocols. Experiments were performed only after the animals were considered to have recovered from surgery and anesthesia and were eating and gaining weight; no animal was studied before the fourth day postoperative. All studies were performed with the animals in a sling, and only after a 30-40 min period demonstrating stable hemodynamic parameters and arterial blood gases. The experiments were divided into two parts to assess cardiovascular responses to systemic and local intra-arterial infusions of ANG II.

Protocol 1. Systemic infusions. Four doses of ANG II $(0.038,0.076,0.19,0.38 \mu \mathrm{g} / \mathrm{kg} \cdot \mathrm{min}$; angiotensin amide, Sigma Chemical, St. Louis, MO, U.S.A.) that had previously been studied in our laboratory $(26,31)$ were used in the present studies. Because animals had different weights and were actively growing, these doses were administered as $\mu \mathrm{g} / \mathrm{kg} \cdot \mathrm{min}$ to account for growth during the study period. After an initial stabilization period of $30 \mathrm{~min}$, each dose of ANG II was infused in random order through the femoral venous catheter using a constant infusion pump (Harvard Apparatus, South Natick, MA, U.S.A.). Each dose was continuously infused for 
$7 \mathrm{~min}$ to achieve steady-state hemodynamic responses while continuously monitoring MAP and HR through an interpolated pressure transducer (model P23XL, Gould Corp., Cleveland, $\mathrm{OH}$, U.S.A.), using the phasic signal to monitor HR, and FmBF with an electromagnetic flow meter (model 551, Carolina Medical). The signals were recorded on an eight-channel recorder (model RS 3800, Gould Corp.) and on the PONEMAH Data Acquisition System (Gould Corp.). The interval between infusions was at least $20 \mathrm{~min}$, allowing all hemodynamic parameters to return to baseline values. FmVR was calculated from MAP divided by FmBF at given points in time (control or steady-state). Arterial blood samples $(0.3 \mathrm{~mL})$ were obtained for measurement of arterial blood gases before each infusion; hematocrit was measured before and at the end of each experiment. Samples were analyzed using a blood gas analyzer (model 113, Instrumentation Laboratory, Lexington, MA, U.S.A.) and Wintrobe capillary method for hematocrit. Animals were studied at 7-14 (period 1), 15-21 (period 2), and 22-35 (period 3) postnatal days to correlate responses with the transition in $\mathrm{AT}$ receptor subtype expression from $\mathrm{AT}_{2}$ to $\mathrm{AT}_{1}$ (18).

Protocol 2. Local infusions. To study the direct effects of ANG II on PVR independent of any systemic effects, e.g. changes in perfusion pressure or ANG II-mediated release of other agonists, we examined the effects of local intra-arterial ANG II infusions through the catheter implanted in the superficial saphenous artery. To more accurately compare the effects of systemic and local ANG II infusions, the femoral or hindlimb circulation must be exposed to similar drug concentrations. The estimated arterial plasma concentrations $(\mathrm{ng} / \mathrm{mL})$ achieved during constant systemic infusions were calculated from the systemic infusion rate $(\mu \mathrm{g} / \mathrm{min})$ divided by the estimated cardiac output $(\mathrm{mL} / \mathrm{min})$ corrected for postnatal age for each animal as determined from observations reported by Woods et al. (2). The local ANG II infusion rate ( $\mathrm{ng} / \mathrm{min}$ ) was then determined from the product of the calculated estimated arterial plasma concentration $(\mathrm{ng} / \mathrm{mL})$ desired times $\mathrm{FmBF}$ $(\mathrm{mL} / \mathrm{min})$ measured with the flowmeter. Because of changes in postnatal weight and cardiac output that occurred during the study period, a broad range of ANG II arterial concentrations were studied. Each animal received four intra-arterial doses of ANG II that were randomly infused. Studies for local ANG II infusions were performed on the same day or within $24 \mathrm{~h}$ of systemic doses to minimize potential developmental changes within each animal. This study was approved by the Institutional Review Board for Animal Research at the University of Texas Southwestern Medical Center at Dallas.

Data analysis. Responses were analyzed as the absolute and relative changes using values obtained immediately before each dose of ANG II and at 5-7 min during the steady-state response to continuous ANG II infusions. To make comparisons between hemodynamic parameters with different units, e.g. MAP and FmBF, and across postnatal age, data are presented as the percent change ( $\% \Delta$ ) from baseline (32). One-way ANOVA for repeated measures was used to analyze the changes in hemodynamic parameters across postnatal age, i.e. between study periods and across doses at each study period. When significance $(p<0.05)$ was observed, Newman-
Keuls multiple comparisons was used to define differences between the periods and/or doses. A paired $t$ test was used to measure changes from baseline. ANOVA for multiple comparisons was used to determine dose-response relationships, followed by Newman-Keuls to define differences at $p<0.05$. Nonparametric analysis was used where appropriate. Regression analysis was also used to examine changes across doses. Data are presented as means \pm SEM. Reported differences are considered significant at $p<0.05$.

\section{RESULTS}

Baseline parameters. The postnatal age, body weight, baseline cardiovascular measurements, arterial blood gases, and hematocrit obtained before each study of the systemic effects of ANG II are presented in Table 1. All of the animals gained weight with increasing postnatal age, values increasing approximately 1.5 -fold $(p<0.001)$ by period 3 . Basal MAP rose approximately $7 \%$ whereas HR fell approximately $28 \%$ across the study periods $(p<0.001)$. FmBF gradually rose approximately $25 \%(p=0.008)$ and FmVR fell in a reciprocal manner. Arterial blood gases obtained before each dose of ANG II in all study periods remained within normal ranges for our laboratory. Although there were no differences in hematocrit before and at the end of each experiment $(p>0.1)$, values fell from $29.8 \%$ during the first study period to $24.8 \%$ during the third study period $(p=0.008)$, likely reflecting the anticipated increase in plasma volume that occurs in the first postnatal month rather than blood loss due to sampling (33). Baseline data obtained before the study of the effects of local intraarterial ANG II infusions did not differ significantly from that observed before the systemic infusions of ANG II (data not shown).

Responses to systemic ANG II infusions. Although there was a difference in baseline MAP and HR at the time of each study period (Table 1), reflecting the increase in postnatal age, baseline values for MAP, HR, and FmBF within each study period and before each dose did not differ (ANOVA, $p>0.05$ ).

Table 1. Postnatal age, weight, baseline hemodynamic variables, arterial blood gases, and hematocrit for each study period prior to the systemic infusion of ANG II in neonatal sheep

\begin{tabular}{|c|c|c|c|}
\hline & $\begin{array}{l}\text { Period } 1 \\
(7-14 \mathrm{~d})\end{array}$ & $\begin{array}{l}\text { Period } 2 \\
(15-21 \mathrm{~d})\end{array}$ & $\begin{array}{l}\text { Period } 3 \\
(22-35 \mathrm{~d})\end{array}$ \\
\hline Number & 6 & 7 & 7 \\
\hline Age (d) & $10.3 \pm 1.1$ & $17.6 \pm 0.8$ & $28.0 \pm 1.6$ \\
\hline Weight (kg) & $5.9 \pm 0.2^{\mathrm{a}}$ & $7.2 \pm 0.2^{\mathrm{b}}$ & $8.7 \pm 0.2^{\mathrm{c}}$ \\
\hline $\begin{array}{l}\text { Mean arterial pressure } \\
(\mathrm{mm} \mathrm{Hg})\end{array}$ & $75.7 \pm 0.8^{\mathrm{a}}$ & $81.2 \pm 1.0^{\mathrm{b}}$ & $80.2 \pm 0.7^{\mathrm{b}}$ \\
\hline Heart rate (bpm) & $209 \pm 7.4^{\mathrm{a}}$ & $184 \pm 6.8^{\mathrm{b}}$ & $150 \pm 4.7^{\mathrm{c}}$ \\
\hline $\begin{array}{l}\text { Femoral blood flow } \\
(\mathrm{mL} / \mathrm{min})\end{array}$ & $60.7 \pm 13.7^{\mathrm{a}}$ & $73.0 \pm 13.1^{\mathrm{b}}$ & $76 \pm 4.9^{\mathrm{b}}$ \\
\hline $\begin{array}{l}\text { Femoral vascular resistance } \\
\qquad(\mathrm{mm} \mathrm{Hg} \cdot \min / \mathrm{mL})\end{array}$ & $3.2 \pm 0.5^{\mathrm{a}}$ & $1.9 \pm 0.2^{\mathrm{ab}}$ & $1.2 \pm 0.1^{\mathrm{b}}$ \\
\hline $\mathrm{pH}$ & $7.415 \pm 0.005$ & $7.406 \pm 0.003$ & $7.422 \pm 0.004$ \\
\hline $\mathrm{PCO}_{2}(\mathrm{~mm} \mathrm{Hg})$ & $35.2 \pm 0.52$ & $35.5 \pm 0.46$ & $36.4 \pm 0.33$ \\
\hline $\mathrm{Po}_{2}(\mathrm{~mm} \mathrm{Hg})$ & $79.3 \pm 1.54$ & $81.8 \pm 1.70$ & $83.4 \pm 0.84$ \\
\hline Hematocrit (\%) & $29.8 \pm 1.19^{\mathrm{a}}$ & $27.9 \pm 0.83^{\mathrm{a}}$ & $24.8 \pm 0.75^{\mathrm{b}}$ \\
\hline
\end{tabular}

Values are means \pm SEM. Different superscripts across rows reflect significant differences between periods as determined by repeated measures ANOVA, $p<0.01$. 
Figure 1 illustrates the simultaneous changes in MAP, HR, and FmBF during a continuous systemic ANG II infusion. Note that the rise in MAP reaches a steady-state response within 1 min of infusion and is associated with a fall in HR that also rapidly achieves a steady state. The dose responses for MAP, $\mathrm{HR}, \mathrm{FmBF}$, and calculated FmVR for each age group are presented in Table 2. Inasmuch as there were significant agedependent changes in MAP and HR, analysis of the absolute values might miss important changes in the responses to ANG II. Therefore, the data were further analyzed using the relative change from baseline $(\% \Delta)$, which takes into account the changes in baseline values and permits a comparison across ages and between hemodynamic parameters (32). At each study period, systemic i.v. ANG II infusions increased MAP at all doses studied $(p<0.01)$, and this response was dose dependent $(p<0.001$; Fig. $2 A)$. There were, however, no significant differences between the three study periods in the systemic pressor response with any ANG II dose investigated (ANOVA, $p>0.05$ ). HR significantly decreased as the MAP increased at all doses $(p<0.05)$ and in all study periods, demonstrating an intact baroreceptor response (Fig. 2B). As with MAP, this response was dose dependent $(p<0.001)$ and did not differ between study periods.

Baseline values for FmBF and FmVR before each ANG II dose did not differ within any study period. As with MAP and HR, the data are presented as the percent change to account for baseline changes in FmBF and FmVR that occurred with increasing age (Table 1), thereby permitting a comparison between age groups. The absolute values are presented in Table 2. In period 1, FmBF rose dose dependently (ANOVA, $p<0.001$; Fig. $3 A$ ); but these increases were only significant with 0.19 and $0.38 \mu \mathrm{g} / \mathrm{kg} \cdot \mathrm{min}$, values rising $20-25 \%$ from baseline. Although FmBF also rose during periods 2 and 3 in response to all doses of ANG II, this was not dose dependent and was not statistically significant except for 0.038 and 0.076 $\mu \mathrm{g} / \mathrm{kg} \cdot \mathrm{min}$ in period 3 . In contrast to the relative changes in FmBF, the rise in FmVR in period 1 was not significant (Fig. $3 B$ ). FmVR did increase dose dependently in periods 2 and 3 (ANOVA, $p<0.001$ ); but there were no differences in the relative responses in the two periods $(p>0.05)$, values increasing approximately $10-30 \%$ at the lowest and highest doses, respectively.

Inasmuch as blood flow to any vascular bed generally reflects the relative changes $(\% \Delta)$ in perfusion pressure, i.e. MAP, and vascular resistance within that vascular bed (32), we compared the simultaneous relative changes in MAP, FmBF, and FmVR. This is necessary, inasmuch as each parameter has a different unit of measurement, which prevents their direct comparison. It also permits one to determine whether changes in FmBF are due to responses in MAP or FmVR (Fig. 4). At 7-14 d postnatal (period 1), the $\% \Delta$ MAP always exceeded the $\% \Delta \mathrm{FmVR}$, and this was significant at 0.19 and $0.38 \mu \mathrm{g} /$ $\mathrm{kg} \cdot \mathrm{min}$, resulting in a significant increase in FmBF at both doses (Fig. 4A). At 15-21 d (period 2), there was a significant dose-dependent rise in $\% \Delta$ MAP and $\% \Delta$ FmVR. Although the relative rise in MAP always exceeded the relative rise in FmVR, this difference was not significant; nonetheless, the $\% \Delta$ FmBF rose modestly at all doses of ANG II (Fig. 4B). A similar pattern of responses occurred at 22-35 d (period 3); i.e. the $\% \Delta$ MAP exceeded or equaled the $\% \Delta$ FmVR and FmBF rose modestly (Fig. 4C).

Responses to local intra-arterial ANG II infusions. Figure 5 illustrates a representative response by MAP, HR, and FmBF to the intra-arterial infusion of ANG II into the hindlimb of a $10 \mathrm{~d}$ postnatal sheep, resulting in a steady-state concentration of $4.3 \mathrm{ng} / \mathrm{mL}$ (period 1). There was a slight rise in MAP at

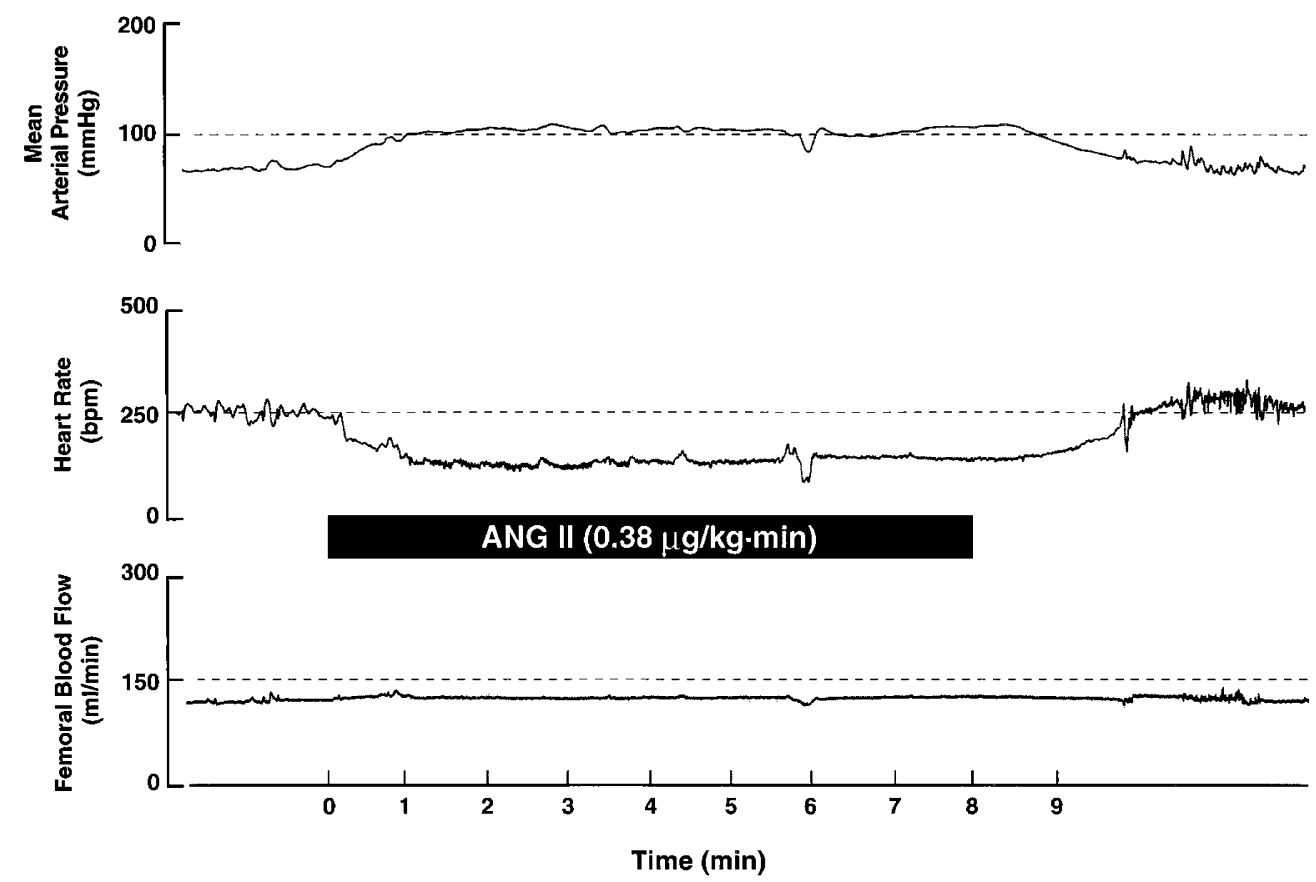

Figure 1. Representative tracing of simultaneous hemodynamic responses to a continuous systemic infusion of ANG II in a chronically instrumented $10 \mathrm{~d}$ postnatal sheep. 
Table 2. Effects of continuous intravenous ANG II infusions in conscious newborn sheep on absolute values of mean arterial pressure (MAP) FmVR, and FmBF in the steady state during the first month postnatal

\begin{tabular}{|c|c|c|c|c|}
\hline & \multicolumn{4}{|c|}{ Dose of ANG II $(\mu \mathrm{g} / \mathrm{min} \cdot \mathrm{kg})$} \\
\hline & 0.038 & 0.076 & 0.19 & 0.38 \\
\hline \multicolumn{5}{|l|}{ Period 1} \\
\hline Heart rate (bpm) & $176 \pm 17.5^{\mathrm{a}}$ & $150 \pm 17.9^{\mathrm{b}}$ & $140 \pm 16.9^{\mathrm{bc}}$ & $138 \pm 18.3^{\mathrm{c}}$ \\
\hline $\mathrm{FmBF}(\mathrm{mL} / \mathrm{min})$ & $53 \pm 21.2^{\mathrm{a}}$ & $70 \pm 31.7^{\mathrm{b}}$ & $70 \pm 30.2^{\mathrm{b}}$ & $75 \pm 30.9^{c}$ \\
\hline FmVR $(\mathrm{mm} \mathrm{Hg} \cdot \min / \mathrm{mL})$ & $3.7 \pm 1.2^{\mathrm{a}}$ & $3.3 \pm 1.0^{\mathrm{a}}$ & $3.6 \pm 1.1^{\mathrm{a}}$ & $3.3 \pm 1.1^{\mathrm{a}}$ \\
\hline Heart rate (bpm) & $161 \pm 16.2^{\mathrm{a}}$ & $144 \pm 14.4^{\mathrm{b}}$ & $121 \pm 11.2^{\mathrm{b}}$ & $116 \pm 10.2^{\mathrm{c}}$ \\
\hline $\mathrm{FmBF}(\mathrm{mL} / \mathrm{min})$ & $74 \pm 26.9^{\mathrm{a}}$ & $85 \pm 27.6^{\mathrm{a}}$ & $75 \pm 26.7^{\mathrm{a}}$ & $73 \pm 27.2^{\mathrm{a}}$ \\
\hline FmVR $(\mathrm{mm} \mathrm{Hg} \cdot \min / \mathrm{mL})$ & $2.0 \pm 0.5^{\mathrm{a}}$ & $1.7 \pm 0.3^{\mathrm{a}}$ & $2.4 \pm 0.6^{\mathrm{b}}$ & $2.8 \pm 0.7^{\mathrm{b}}$ \\
\hline \multicolumn{5}{|l|}{ Period 3} \\
\hline MAP (mm Hg) & $97.3 \pm 3.5^{\mathrm{a}}$ & $105.1 \pm 3.7^{\mathrm{b}}$ & $115.4 \pm 4.5^{\mathrm{c}}$ & $125 \pm 5.0^{\mathrm{d}}$ \\
\hline Heart rate (bpm) & $135 \pm 10.1^{\mathrm{a}}$ & $113 \pm 9.8^{\mathrm{b}}$ & $103 \pm 8.1^{\mathrm{b}}$ & $104 \pm 4.3^{\mathrm{b}}$ \\
\hline
\end{tabular}

Values are means \pm SEM. Period 1 was 7-14 d; period 2, 15-21 d; period 3, 22-35 d. Baseline values are presented in Table 1. Different superscripts across rows reflect significant differences at $p<0.001$ between responses to each dose of ANG II as determined by repeated measures ANOVA.
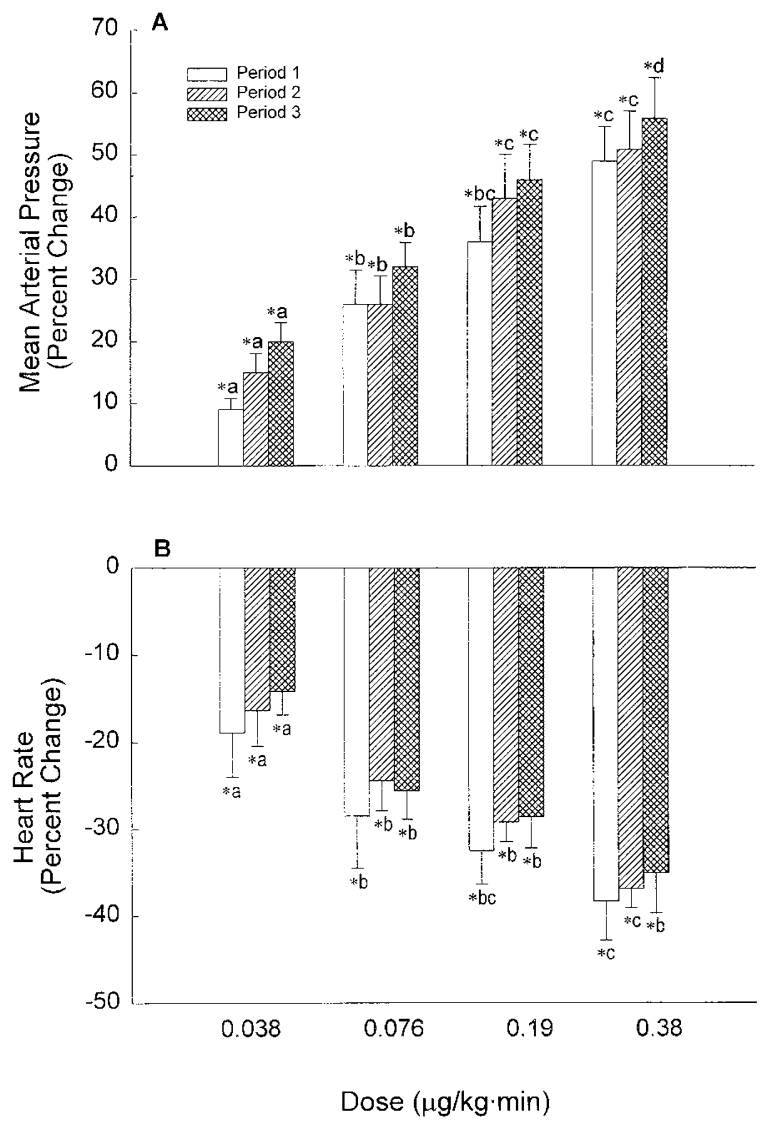

Figure 2. Relative changes in mean arterial pressure $(A)$ and heart rate $(B)$ during systemic ANG II infusions in postnatal sheep at 7-35 d after birth $(n=7)$. Responses for each study period are illustrated. Asterisks represent significant differences from baseline values as determined by paired $t$ test, $p<0.05$. Different letters represent significant differences across doses within an age group as determined by repeated measures ANOVA, $p<0.05$. Data are means \pm SEM.

approximately 2 min of infusion with a reciprocal, but minimum fall in HR; FmBF was unchanged. At lower rates of infusion and thus lower arterial concentrations of ANG II, there were no alterations in MAP or HR at any age studied.
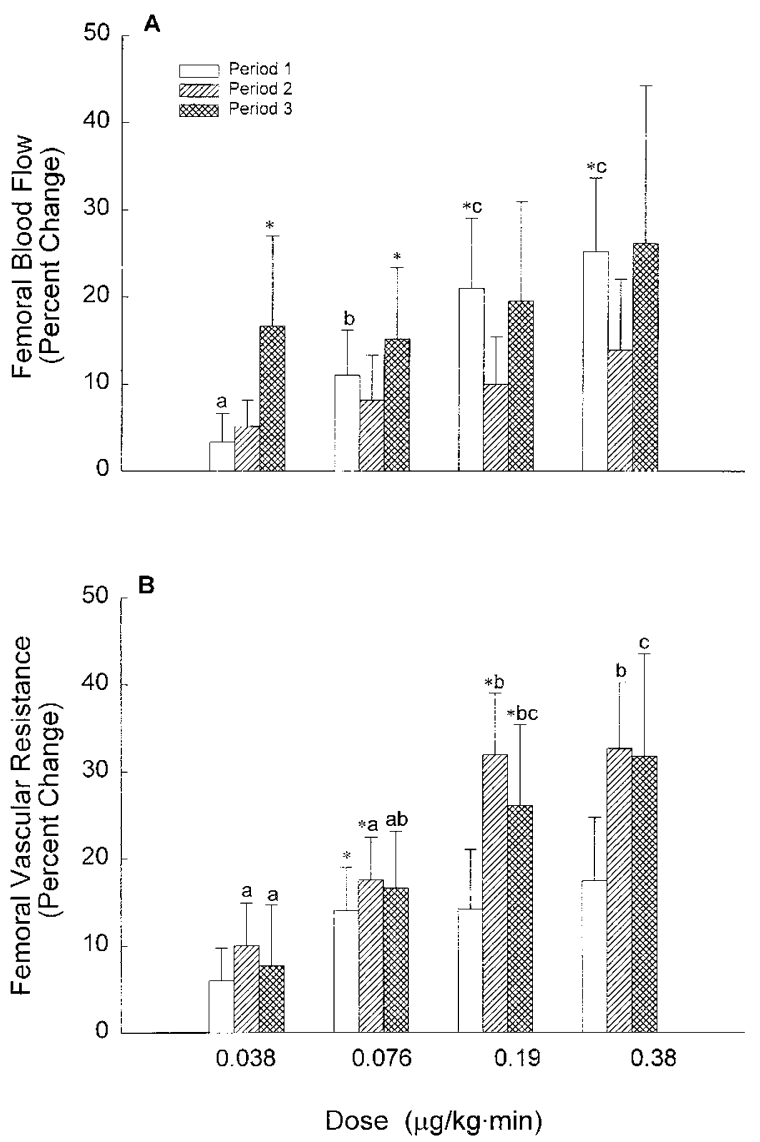

Figure 3. Relative changes in femoral blood flow $(A)$ and vascular resistance $(B)$ during systemic ANG II infusions in postnatal sheep at 7-35 d after birth $(n=7)$. Responses for each study period are illustrated. Asterisks represent significant differences from baseline values as determined by paired $t$ test, $p<$ 0.05 . Different letters represent significant differences across doses within an age group as determined by repeated measures ANOVA, $p<0.05$. Data are means \pm SEM.

Similar responses were observed in all study periods during intra-arterial ANG II infusions into the hindlimb. In contrast to that observed during systemic ANG II infusions, there were no 

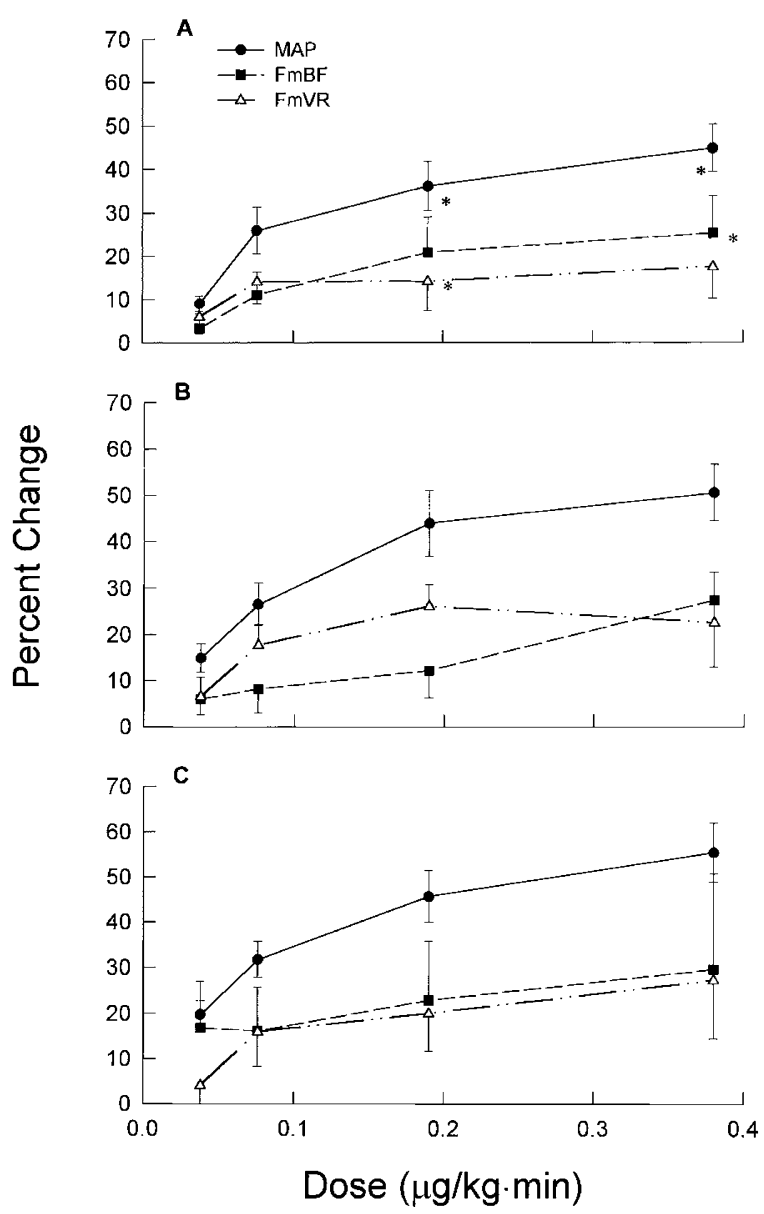

Figure 4. Relationship between the simultaneous relative changes in MAP, FmBF, and FmVR during systemic ANG II infusions in postnatal sheep at 7-14 d $(A), 15-21 \mathrm{~d}(B)$, and 22-35 d $(C)$ after birth. Asterisks represent significant differences between changes in MAP and FmVR as determined by ANOVA, $p<0.05$. Data are presented as means \pm SEM.

significant changes in FmBF in any animal studied during any study period $(p>0.1)$. Further, FmVR was unchanged $(p>$ 0.1 ) except in period 1, at which time FmVR rose modestly and variably, but with only the highest doses studied and only after MAP was observed to rise. When MAP increased, this occurred approximately 2 min after starting the local intra-arterial infusion of ANG II compared with within 1 min during the i.v. or systemic infusion of the peptide (Fig. 1). This delay in the rise in MAP during the local intra-arterial infusions suggests that ANG II had reached the systemic circulation. There were no changes in MAP during the other study periods $(p>0.1)$, and heart rate did not change $(p>0.1)$ in any period during intra-arterial ANG II infusions.

\section{DISCUSSION}

The mechanisms regulating fetal and neonatal blood pressure are complex and incompletely understood. In general, this is dependent upon a variety of maturational changes in vascular function and reactivity, which may include changes in VSM contractile protein expression, ion channel expression and function, endothelial function, and receptor expression. For example, VSM contractile protein expression is developmen- tally regulated and appears to modify vascular responses in fetal and newborn sheep (34). Although the RAS is considered an important determinate of fetal and neonatal blood pressure through the effects of ANG II, AT receptor subtype expression in VSM from fetal and neonatal sheep also is developmentally regulated, and predominance of the adult $\mathrm{AT}_{1}$ is not evident until $>2$ wk postnatal $(18,19,35)$. Thus, the mechanism(s) whereby ANG II regulates blood pressure before and after birth is unclear. In the present study, we observed that systemic ANG II infusions dose dependently increased MAP during the first month after birth, but vascular resistance in the hindlimb increased only modestly and FmBF rose or was unaffected. Moreover, we observed for the first time that, in contrast to adult sheep (12), local intra-arterial ANG II infusions did not alter neonatal FmVR or MAP, suggesting that ANG II may have minimal direct effects on PVR in the first month after birth and that responses to systemic infusions may reflect secondary mediators. Thus, it is unclear how ANG II modulates MAP after birth.

Blood pressure increases after birth $(1,36-40)$, and this appears to occur in at least two stages. Immediately after birth there is an initial rise in MAP, which is in part related to the loss of the low-resistance placental vascular bed, closure of vascular shunts, and increased circulating levels of vasoconstrictors $(1,36,37)$. This is followed by a gradual rise in basal MAP, which is very likely due to entirely different mechanisms. In the present study, basal MAP $1 \mathrm{wk}$ postnatal was almost twice that reported in fetal sheep $(1,7,9,31)$, and values continued to rise until after the second week postnatal. This pattern is consistent with other studies in neonatal sheep $(38,39)$ and more recent data in preterm neonates $(40)$. This secondary rise in MAP is not well studied and could reflect several mechanisms, including decreases in circulating levels of fetally derived vasodilators, increases in PVR due to enhanced vascular reactivity or increased plasma levels of vasoconstrictors, and/or increases in cardiac output. Whereas removal of a prenatal circulating vasodilator such as placental estrogen is intriguing $(41,42)$, this has not been studied. It also is unclear whether there are changes in production of local vasodilators such as prostacyclin (43). If the rise in MAP is due to gradual increases in PVR $(2,44,45)$, one would expect an increase in peripheral vascular reactivity, sympathetic tone, and/or circulating levels of agents such as ANG II. However, existing data do not support any of these as occurring after birth $(29,38,46)$. For example, plasma ANG II falls in the human neonate as MAP rises, demonstrating an intact pressormediated negative feedback mechanism (46). In the present study hindlimb vascular resistance decreased rather than increased with advancing postnatal age and FmBF rose, as one might anticipate in a growing neonate. It is possible the hindlimb is not representative of other peripheral vascular beds and thus does not accurately predict total PVR. If it is representative, one would expect MAP to fall with increasing age unless there were parallel increases in cardiac output, which are indeed reported $(2,44)$. Inasmuch as HR also fell with advancing postnatal age, the present observations suggest that increases in cardiac output mediated through an increase in stroke volume may modulate the postnatal rise in MAP. 

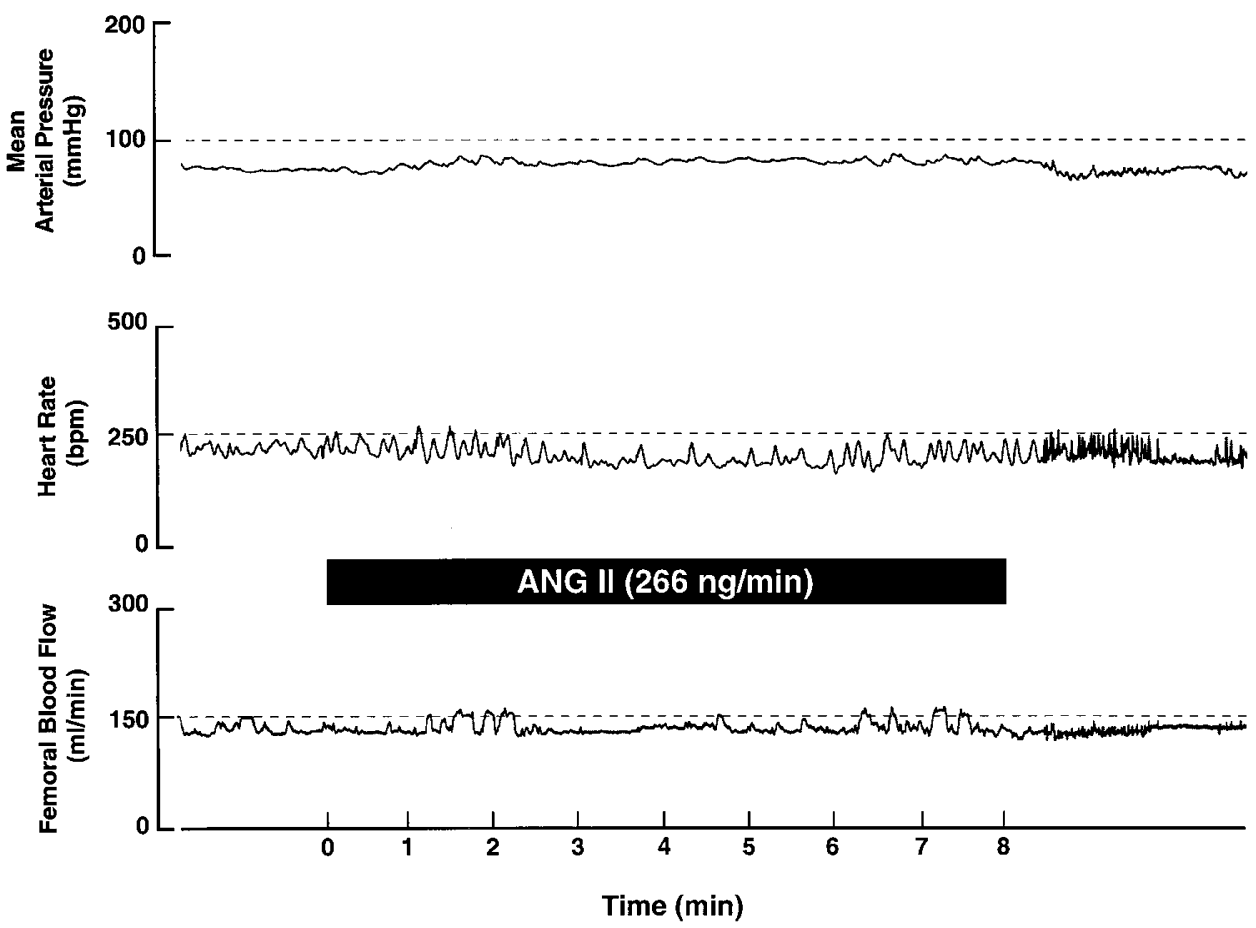

Figure 5. Representative tracing of simultaneous hemodynamic responses to a continuous local intra-arterial infusion of ANG II in a chronically instrumented $10 \mathrm{~d}$ postnatal sheep.

As noted above, as basal MAP rose with increasing postnatal age there was a parallel fall in resting HR. This reciprocal relationship between MAP and HR generally suggests either a resetting of the baroreceptor response (4) or a change in parasympathetic activity, which is reported to increase after birth $(38,48)$. Although the level of parasympathetic activity can alter neonatal HR, the balance with sympathetic or adrenergic activity is not related to postnatal age (38). Therefore, the gradual fall in HR after birth is entirely due to increases in parasympathetic outflow. An alternate explanation is that the postnatal fall in HR is due to alterations in the intrinsic conducting mechanisms of the heart (47).

Consistent with previous observations (28-30), systemic ANG II infusions increased MAP dose-dependently throughout the study period; but the responses were not age-dependent. There also were parallel dose-dependent increases in FmVR, but, as with MAP, responses were unchanged with age. This suggests that vascular reactivity is unchanged during the study period, which is consistent with earlier reports $(29,38)$, or that vascular sensitivity increases; however, potential increases in the clearance and/or distribution of ANG II in the first month postnatal may result in similar pressor responses at all ages. Thus, Wilson et al. (29) suggested that one had to use the plasma level of ANG II rather than the dose infused to evaluate age-dependent changes in newborn sheep, implying that ANG II clearance increases during the postnatal period and is agedependent. In fetal sheep ANG II clearance rate is 10 -fold greater than the adult, $-650 \mathrm{~mL} / \mathrm{min} \cdot \mathrm{kg}$ versus $75 \mathrm{~mL} / \mathrm{min} \cdot \mathrm{kg}$, and is almost entirely due to placental clearance $(49,50)$. Until this was reported, many concluded the ovine fetus was less responsive to ANG II than the adult. Thus, a fall in ANG II clearance is anticipated immediately after birth and possibly an increase in clearance thereafter. However, ANG II clearance has not been examined in the newborn and may provide one explanation for the lack of an age-dependent effect on MAP.

Although FmVR rose in association with the rise in MAP during systemic ANG II infusions, perfusion pressure always exceeded FmVR. Thus, the effects of ANG II on the hindlimb appear to be attenuated. This suggests that the rise in MAP may not be dependent solely on ANG II-mediated increases in PVR. The difference in peripheral and systemic responses to ANG II could be due to the predominance of $\mathrm{AT}_{2}$ expression in hindlimb VSM before 2 wk postnatal $(18,19)$. Alternatively, this could be due to the presence of a locally produced ANG II antagonist(s). This has been observed in the fetus and adult and includes vasodilating prostaglandins and nitric oxide, the synthesis of which can be augmented by ANG II through endothelial $\mathrm{AT}_{1}$ receptors $(35,43,51,52)$. The attenuation could also reflect the antagonizing effects of the VSM AT $\mathrm{AT}_{2}$ receptor on $\mathrm{AT}_{1}$-mediated vasoconstriction $(24,53)$. This becomes especially important after $2 \mathrm{wk}$ postnatal when the $\mathrm{AT}_{1}$ gradually replace $\mathrm{AT}_{2}$ in VSM (18). Another explanation for the difference (or lack of difference) in the responses in FmVR and MAP to systemic ANG II may be that increases in FmVR reflect myogenic responses secondary to the rise in perfusion pressure (27) and some degree of autoregulation in the hindlimb as recently observed in fetal sheep (26). This would explain why FmBF did not fall despite modest increases in FmVR. It also would provide a mechanism, albeit indirect, whereby ANG II participates in regulating PVR and MAP.

Studies of the mechanisms responsible for the pressor responses to systemic ANG II infusions are complicated by potential effects of the peptide on the CNS, release of secondary mediators, and direct cardiac effects $(4,13-16)$. To address 
this, we examined the effects of local intra-arterial ANG II infusions on FmBF and FmVR. To our surprise, local ANG II infusions did not evoke local vascular responses at any time in the first month postnatal. This observation is novel and contrasts sharply with that observed in adult pregnant and nonpregnant sheep (10). As discussed earlier, this could be due to local or ANG II-stimulated synthesis of local antagonists, including prostacyclin and/or nitric oxide $(35,43,51,52)$, the absence of $\mathrm{AT}_{1}$ expression in the VSM, or the inhibiting effects of the $\mathrm{AT}_{2}$ on $\mathrm{AT}_{1}$-mediated vasoconstriction $(24,53)$. If $\mathrm{AT}_{1}$ receptors are not present in VSM (18), an alternative explanation for the effects of systemic ANG II must be sought. ANG II is also capable of mediating vasoconstriction through indirect mechanisms. For example, it increases the activity of the autonomic nervous system by stimulating sympatho-excitatory neurons $(4,14)$, decreases re-uptake of norepinephrine by nerve endings (54), enhances epinephrine release by the adrenal medulla (15), stimulates the release of vasopressin, a potent vasoconstrictor in newborn and adult sheep $(14,16)$, and increases VSM synthesis and/or release of endothelin (55). None of these have been examined in the newborn. Support for such a mechanism is obtained from our observation that high doses of locally infused ANG II caused a delayed rise in MAP, which was followed by a rise in FmVR, suggesting overflow of the peptide into the systemic circulation. In what may be an analogous situation, the adult uterine vascular bed predominantly expresses $\mathrm{AT}_{2}$ in the $\operatorname{VSM}(21,23)$. It also demonstrates dose-dependent increases in vascular resistance during systemic ANG II infusions that are less than systemic responses $(21,32)$. Furthermore, as seen in the neonatal hindlimb, it too is unresponsive to intra-arterial ANG II infusions until there is evidence that the peptide has spilled over into the systemic circulation (56). More recently, we (57) observed that $\alpha$-adrenergic blockade inhibits the uterine responses to systemic ANG II infusions. This has not been examined in newborn animals and may provide important insights into the mechanisms of ANG II-induced increases in MAP and FmVR after birth.

In the present study, we provided data suggesting that ANG II may have minimal direct effects on PVR, and that its effects on MAP may be mediated indirectly or through central mechanisms. We have demonstrated during the first month after birth that systemic ANG II infusions increase MAP dose dependently and are associated with modest increases in FmVR, which never exceed the relative rise in MAP, thereby maintaining FmBF. However, we have shown for the first time that local ANG II infusions do not affect FmVR or FmBF, possibly due to the predominance of $\mathrm{AT}_{2}$ receptor expression in VSM of the hindlimb of neonatal sheep (18), and that the changes in FmVR and possibly PVR during systemic ANG II infusions may be due to release of another mediator. Although other explanations are possible, use of the present animal model will permit us to address these questions because the hindlimb vascular bed can be isolated and studied independent of systemic responses and modifications in perfusion pressure.

\section{REFERENCES}

1. Davidson D 1987 Circulating vasoactive substances and hemodynamic adjustments at birth in lambs. J Appl Physiol 63:676-684

2. Woods Jr JR, Dandavino A, Brinkman III CR, Nuwayhid B, Assali NS 1978 Cardiac output changes during neonatal growth. Am J Physiol 234:H520-H524

3. Agata Y, Hiraishi S, Misawa H, Hirota H, Nowatari M, Hiura K, Fujino N, Oguchi K, Horiguchi Y 1994 Regional blood flow distribution and left ventricular output during early neonatal life: a quantitative ultrasonographic assessment. Pediatr Res $36: 805-810$

4. Segar JL 1997 Ontogeny of the arterial and cardiopulmonary baroreflex during fetal and postnatal life. Am J Physiol 273:R457-R471

5. Pipkin FB, Kirkpatrick SML, Lumbers ER, Mott JC 1974 Renin and angiotensin-like levels in fetal, newborn and adult sheep. J Physiol 241:575-588

6. Eliot RJ, Klein AH, Glatz TH, Nathanielsz PW, Fisher DA 1981 Plasma norepinephrine, epinephrine, and dopamine concentrations in maternal and fetal sheep during spontaneous parturition and in premature sheep during cortisol-induced parturition. Endocrinology 108:1678-1682

7. Iwamoto HS, Rudolph AM 1979 Effects of endogenous angiotensin II on the fetal circulation. J Dev Physiol 1:283-293

8. Siegel SR, Fisher DA 1979 The effects of angiotensin blockade and nephrectomy on the renin-angiotensin-aldosterone system in the newborn lamb. Pediatr Res 13:603605

9. Mathai ML, Pennington GL, Mckinley MJ 1997 The effect of angiotensin AT receptor blockade in the brain on the maintenance of blood pressure during haemorrhage in sheep. Acta Physiol Scand 161:495-502

10. McLaughlin MK, Westney DJ 1985 An examination of vascular reactivity during pregnancy in the chronic ewe model. Am J Obstet Gynecol 151:479-483

11. Fujii AM, Vatner SF 1985 Direct versus indirect pressor and vasoconstrictor actions of angiotensin in conscious dogs. Hypertension 7:253-261

12. Vollmer RR, Meyers-Schoy SA, Marinelli RR 1991 Mechanisms involved in angiotensin II induced increases in cardiac output in pithed rats. Clin Exp Hypertens A13:1433-1445

13. Naden RP, Gant Jr FG, Rosenfeld CR 1984 The pressor response to angiotensin II: the roles of peripheral and cardiac responses in pregnant and nonpregnant sheep. Am J Obstet Gynecol 148:450-457

14. Breuhaus BA, Chimoskey JE 1990 Hemodynamic and behavioral effects of angiotensin II in conscious sheep. Am J Physiol 258:R1230-R1237

15. Butler DG, Butt DA, Puskas D, Oudit GY 1994 Angiotensin II-mediated catecholamine release during pressor response in rats. J Endocrinol 142:19-28

16. Siegel SR, Weitzman RE, Fisher DA 1979 Endogenous angiotensin stimulation of vasopressin in the newborn lamb. J Clin Invest 63:287-293

17. Dudley DT, Panek RL, Major TC, Lu GH, Bruns RF, Klinkefus BA, Hodges JC, Weishaar RE 1990 Subclasses of angiotensin II binding sites and their functional significance. Mol Pharmacol 38:370-377

18. Cox BE, Rosenfeld CR 1999 Ontogeny of vascular angiotensin II receptor subtype expression in ovine development. Pediatr Res 45:414-424

19. Burrell JH, Hegarty BD, McMullen JR, Lumbers ER 2001 Effects of gestation on ovine fetal and maternal angiotensin receptor subtypes in the heart and major vessels. Exp Physiol 86:1:71-82

20. Bottari SP, Gasparo M, Steckelings UM, Levens NR 1993 Angiotensin II receptor subtypes: characterization, signalling mechanisms, and possible physiological implications. Neuroendocrinol 14:123-171

21. Cox BE, Rosenfeld CR, Kalinyak JE, Magness RR, Shaul PW 1996 Tissue specific expression of vascular smooth muscle angiotensin II receptor subtypes during ovine pregnancy. Am J Physiol 271:H212-H221

22. Cox BE, Ipson MA, Shaul PW, Kamm KE, Rosenfeld CR 1993 Myometrial angiotensin II receptor subtypes change during ovine pregnancy. J Clin Invest 92:22402248

23. Cox BE, Word RA, Rosenfeld CR 1996 Angiotensin II receptor characteristics and subtype expression in uterine arteries and myometrium during pregnancy. J Clin Endocrinol Metab 81:49-58

24. Tsutsumi Y, Matsubara H, Masaki H, Kurihara H, Murasawa S, Takai S, Miyazaki M, Nozawa Y, Ozono R, Nakagawa K, Miwa T, Kawada N, Mori Y, Shibasaki Y, Tanaka Y, Fujiyama S, Koyama Y, Fujiyama A, Takahashi H, Iwasaka T 1999 Angiotensin II type 2 receptor overexpression activates the vascular kinin system and causes vasodilation. J Clin Invest 104:925-935

25. McMullen JR, Gibson KJ, Lumers ER, Burrell JH, WJ 1999 Interactions between $\mathrm{AT}_{1}$ and $\mathrm{AT}_{2}$ receptors in uterine arteries from pregnant ewes. Eur $\mathrm{J}$ Pharmacol 378:195-202

26. Kaiser JR, Cox BE, Roy TA, Rosenfeld CR 1998 Differential development of umbilical and systemic arteries. I. ANG II receptor subtype expression. Am J Physiol 274:R797-R807

27. Davis MJ 1993 Myogenic response gradient in an arteriolar network. Am J Physiol 264:H2168-H2179

28. Goetzman BW, Bennett SH 1991 Hemodynamic responses to angiotensin II in the newborn lamb. Dev Pharmacol Ther 17:63-69

29. Wilson TA, Kaiser DL, Wright Jr EM, Ortt EM, Freedlender AE, Peach MJ, Carey RM 1981 Importance of plasma angiotensin concentrations in a comparative study of responses to angiotensin in the maturing newborn lamb. Hypertension 3(suppl II): $18-24$

30. Scroop GC, Marker JD, Stankewytsch-Janusch B, Seamark RF 1986 Angiotensin I and II in the assessment of baroreceptor function in fetal and neonatal sheep. J Dev Physiol 8:123-137

31. Yoshimura T, Magness RR, Rosenfeld CR 1990 Angiotensin II and $\alpha$-agonist. I. Responses of ovine fetoplacental vasculature. Am J Physiol 259:H464-H472 
32. Naden RP, Rosenfeld CR 1981 Effect of angiotensin II on uterine and systemic vasculature in pregnant sheep. J Clin Invest 68:468-474

33. Brans YW, Andrew DS, Schwartz CA, Carey KD 1991 Serial estimates of body water content and distribution during the first month in baboons. J Med Primatol 20:75-81

34. Arens Y, Chapados RA, Cox BE, Kamm KE, Rosenfeld CR 1998 Differential development of umbilical and systemic arteries. II. Contractile proteins. Am J Physiol 274:R1815-R1823

35. Segar JL, Barna TJ, Acarregui MJ, Lamb FS 2001 Responses of fetal ovine systemic and umbilical arteries to angiotensin II. Pediatr Res 49:826-833

36. Assali NS 1967 Some aspects of fetal life in utero and the changes at birth. Am J Obstet Gynecol 97:324-331

37. Dawes GS 1961 Changes in the circulation at birth. Br Med Bull 17:148-153

38. Woods Jr JR, Dandavino A, Murayama K, Brinkman III CR, Assali NS 1977 Autonomic control of cardiovascular functions during neonatal development and in adult sheep. Circ Res 40:401-407

39. Wilson TA, Kaiser DL, Wright Jr EM, Peach MJ, Carey RM 1981 Ontogeny of blood pressure and the renin-angiotensin-aldosterone system. Circ Res 49:416-423

40. Engle WD 2001 Blood pressure in the very low birth weight neonate. Early Hum Dev 62:97-130

41. Rosenfeld CR 1989 The Uterine Circulation. Perinatology Press, Ithaca, NY

42. Trotter A, Maier L, Grill H-J, Kohn T, Heckman M, Pohlandt F 1999 Effects of postnatal estradiol and progesterone replacement in extremely preterm infants. J Clin Endocrinol Metab 84:4531-4535

43. Yoshimura T, Magness RR, Rosenfeld CR 1990 Angiotensin II and alpha-agonist. II Effects on ovine fetoplacental prostaglandins. Am J Physiol 259:H473-H479

44. Minoura S, Gilbert RD 1987 Postnatal change of cardiac function in lambs: effects of ganglionic block and afterload. J Dev Physiol 9:123-135

45. Wu PYK, Wong WH, Guerra G, Miranda R, Godoy RR, Preston B, Schoentgen S, Levan NE 1980 Peripheral blood flow in the neonate. 1. Changes in total, skin, and muscle blood flow with gestational and postnatal age. Pediatr Res 14:1374-1378

46. Pipkin FB, Smales ORC 1977 A study of factors affecting blood pressure and angiotensin II in newborn infants. J Pediatr 91:113-119
47. Levy MN, Zieske H 1969 Autonomic control of cardiac pacemaker activity and atrioventricular transmission. J Appl Physiol 27:465-470

48. Zugaib M, Forsythe AB, Nuwayhid B, Lieb SM, Tabsh K, Erkkola R, Ushioda E, Brinkman III CR, Assali NS 1980 Mechanisms of beat-to-beat variability in the heart rate of the neonatal lamb. I. Influence of the autonomic nervous system. Am J Obstet Gynecol 138:444-452

49. Rosenfeld CR, Gresores A, Roy TA, Magness RR 1995 Comparison of ANG II in fetal and pregnant sheep: metabolic clearance and vascular sensitivity. Am J Physiol 268:E237-E247

50. Stanley JR, Giammattei CE, Sheikh AU, Green JL, Zehnder T, Rose JC 1997 Effects of chronic infusion of angiotensin II on renin and blood pressure in the late-gestation fetal sheep. Am J Obstet Gynecol 176:931-937

51. Magness RR, Rosenfeld CR, Hassan A, Shaul PW 1996 Endothelial vasodilator production by uterine and systemic arteries. I. Effects of ANG II on $\mathrm{PGI}_{2}$ and $\mathrm{NO}$ in pregnancy. Am J Physiol 270:H1914-H1923

52. Boulanger CM, Caputo L, Levy BI 1995 Endothelial AT1-mediated release of nitric oxide decreases angiotensin II contractions in rat carotid artery. Hypertension 26:752-757

53. Brede M, Hein L 2001 Transgenic mouse models of angiotensin receptor subtype function in the cardiovascular system. Regul Pept 96:125-132

54. Khairallah PA 1972 Action of angiotensin on adrenergic nerve endings: inhibition of norepinephrine uptake. Fed Proc 31:1351-1357

55. d'Uscio LV, Shaw S, Barton M, Luscher TF 1998 Losartan but not verapamil inhibits angiotensin II-induced tissue endothelin-1 increase: Role of blood pressure and endothelial function. Hypertension 31:1305-1310

56. Cox BE, Williams CE, Rosenfeld CR 2000 Angiotensin II indirectly vasoconstricts the ovine uterine circulation. Am J Physiol 278:R337-R344

57. Cox BE, Roy TA, Rosenfeld CR 1999 Different mechanisms mediate angiotension II-induced vasoconstriction in uterine and systemic vascular beds of pregnant and non-pregnant ewes. J Soc Gynecol Invest 6:189A(abstr) 